EESTI NSV TEADUSTE AKADEEMIA TOIMETISED. 21. KÖIDE KEEMIA * GEOLOOGIA. 1972, NR. 3

ИЗВЕСТИЯ АКАДЕМИИ НАУК ЭСТОНСКОЙ ССР. ТОМ 21 ХИМИЯ * ГЕОЛОГИЯ. 1972, № 3

\title{
СОВРЕМЕННАЯ СТРУКТУРА ПОВЕРХНОСТИ ФУНДАМЕНТА ЭСТОНИи
}

Данные глубокого бурения и геофизических исследований, выполненных на территории Эстонии до 1970 г., позволяют осветить основные черты современного структурного плана поверхности фундамента.

В итоге обобщения этих материалов составлена предлагаемая карта рельефа поверхности фундамента и кровли магнитных пород (рис. 1). Она построена на основе данных перфокартотеки скважин Управления геологии СМ ЭССР и результатов геофизических исследований, проведенных различными организациями (Институтом геологии АН ЭССР, Управлением геологин СМ ЭССР, Западным геофизическим трестом и трестом «Спецгеофизика»). Использовано более 500 определений глубины залегания фундамента: по скважннам - более 100, по результатам сейсморазведки (точечным зондированием корреляционным методом преломленных волн - ТЗ КМПВ) - около 400 и примерно 2300 определений глубины залегания магнитных пород путем расчета магнитных аномалий.

Стратоизогипсы поверхности фундамента проведены раздельно по данным бурения и по результатам сейсморазведки. Погрешность последних можно оценить лишь приближенно по немногим скважинам, не учтенным при интерпретации сейсмических материалов. Сопоставление интерполированных по данным ТЗ КМПВ абсолютных отметок поверхности фундамента для скважин Карула $(--508$ м) и Печоры $(-506$ м) с цанными скважин (соответственно -493 и -529 м) указывает на относительную погрешность порядка $\pm 4 \%$.

Для построения стратоизогипс кровли магнитных пород результаты расчетов по магнитным аномалиям обработаны статистически способом, предложенным Н. Михайловым (1960). Изолинии проведены по абсо. літным отметкам, осредненным по 10--50 точкам расчета и отнесенным к центру трапецевидных участков осреднения площадью $300-900 \kappa м^{2}$.

Структурные карты, составленные по данным массовых вычислений глубин залегания магнитных пород, обычно отождествляют с рельефом современной поверхности фундамента. Достоверность их оценивается путем сравнения с данными бурения. Такое сравнение проведено-по интерполированным значениям осредненных вычисленных глубин для 60

Рис. 1. Карта рельефа поверхности фундамента и кровли магнитных пород. 1, 2 стратоизогипсы поверхности фундамента: 1 - по данным бурения, 2 - по данным сейсморазведки; 3 - стратоизогипсы кровли магнитных пород; 4 - буровые скважины; 5 - точки Т3 КМПВ; 6 - точки осреднения вычнсленных абсолютных отметок кровли магнитных пород; 7 - локальные поднятия: I - Мынистеское, II - Ульястеское, III Азериское, IV - Таллинскос, V - Палукюлаское. 


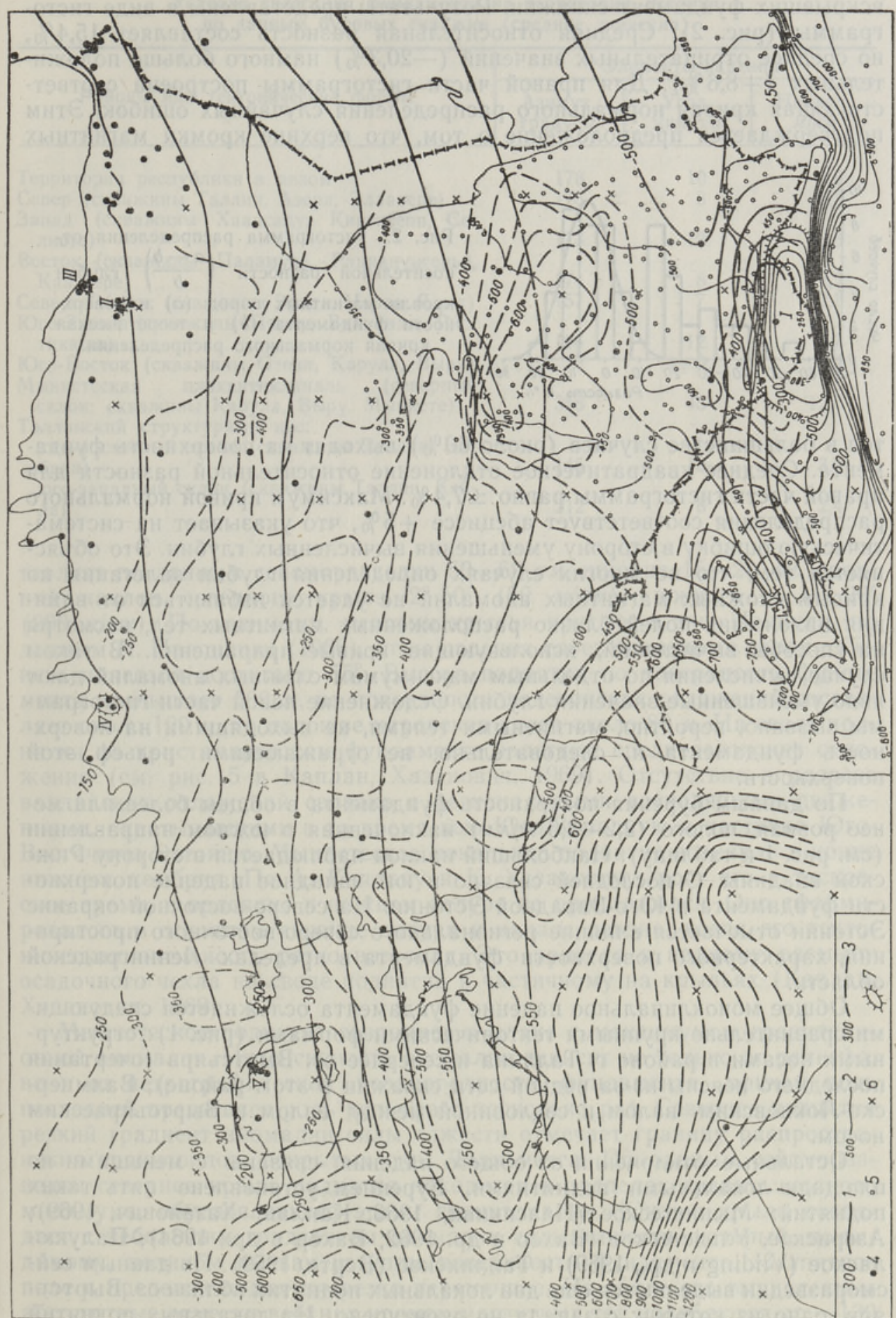


вскрывших фундамент скважин. Результаты представлены в виде гистограммы (рис. 2). Средняя относительная разность составляет $15,4 \%$, но среднее отрицательных значений $(-20,3 \%)$ намного больше положительных $(+8,6 \%)$. Для правой части гистограммы построена соответствующая кривая нормального распределения случайных ошибок. Әтим подтверждается предположение о том, что верхние кромки магнитных

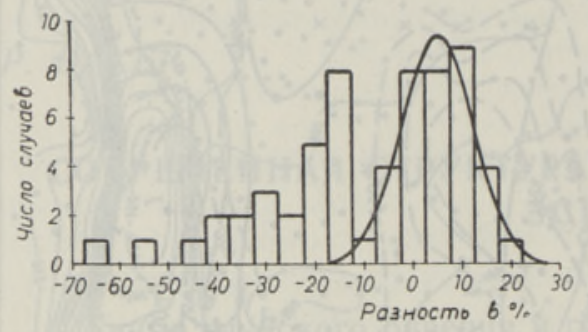

Рис. 2. Гистограмма распределения относительной разности $\left(\frac{a-b}{b}\right)$ глубин кровли магнитных пород $(a)$ и поверх. ности фундамента $(b)$ и теоретическая кривая нормального распределения.

тел в большинстве случаев (около 60\%) выходят на поверхность фундамента. Среднее квадратическое отклонение относительной разности для правой части гистограммы равно $\pm 7,4 \%$. Максимум кривой нормального распределения соответствует абсциссе $+5 \%$, что указывает на систематическую ошибку в сторону уменьшения вычисленных глубин. Әто объясняется тем, что во многих случаях определения глубин залегания по крнвым сложных магнитных аномалий не удается избавиться от влияния наложения полей близко расположенных магнитных тел, несмотря на способы вычислений, использующие кривые приращения. В таком случае вычисления по отдельным максимумам сложных аномалий дают явно уменьшенные значения глубин. Осложнение левой части гистограммы вызвано, вероятно, магнитными телами, не выходящими на поверхность фундамента и, следовательно, не отражающими рельеф этой поверхности.

По данным бурения поверхность фундамента в общем более или менее ровная, полого $(2,2-3,6$ м/км $)$ наклоненная в южном направлении (см. рис. 1 и таблицу). Наибольший наклон наблюдается в сторону Рижской впадины. С последней связано и юго-западное падение поверхности фундамента в Юго-Западной Әстонии. На северо-восточной окраине Эстонии отмечается влиянне регионального северо-восточного простирания, характерного поверхности фундамента в пределах Ленинградской области.

Общее моноклинальное падение фундамента осложняется следующими сравнительно крупными тектоническими формами (рис. 1): структурными носами в районе г. Таллина и севернее оз. Выртсъярв (очертания последнего неясны из-за редкой сети скважин в этом районе), Валмиерско-Локновским валом и седловиной между валом и Выртсъярвеским носом.

Остальные отклонения от общего падения связаны с меньшими по площади локальными поднятиями. Бурением установлено пять таких поднятий: Мынистеское (Паасикиви, 1966; Каплан, Хазанович, 1969), Азериское, Ульястеское (Вахер и др. 1962; Вахер и др., 1964), Палукюлаское (Viiding и др., 1969) и Таллинское (Верте, 1959). По данным сейсморазведки выделяются еще два локальных поднятия вблизи оз. Выртсъярв, одно из которых с запада не оконтурено. Из локальных поднятий лучше изучены Мынистеское, Ульястеское и Палукюлаское.

Крупнейшее из них, Мынистеское поднятие, является частью Валмиерско-Локновского вала (ряда плакантиклиналей). Длина его сос- 
Условия залегания фундамента на территории Эстонии по данным буровых скважин (средние значения)

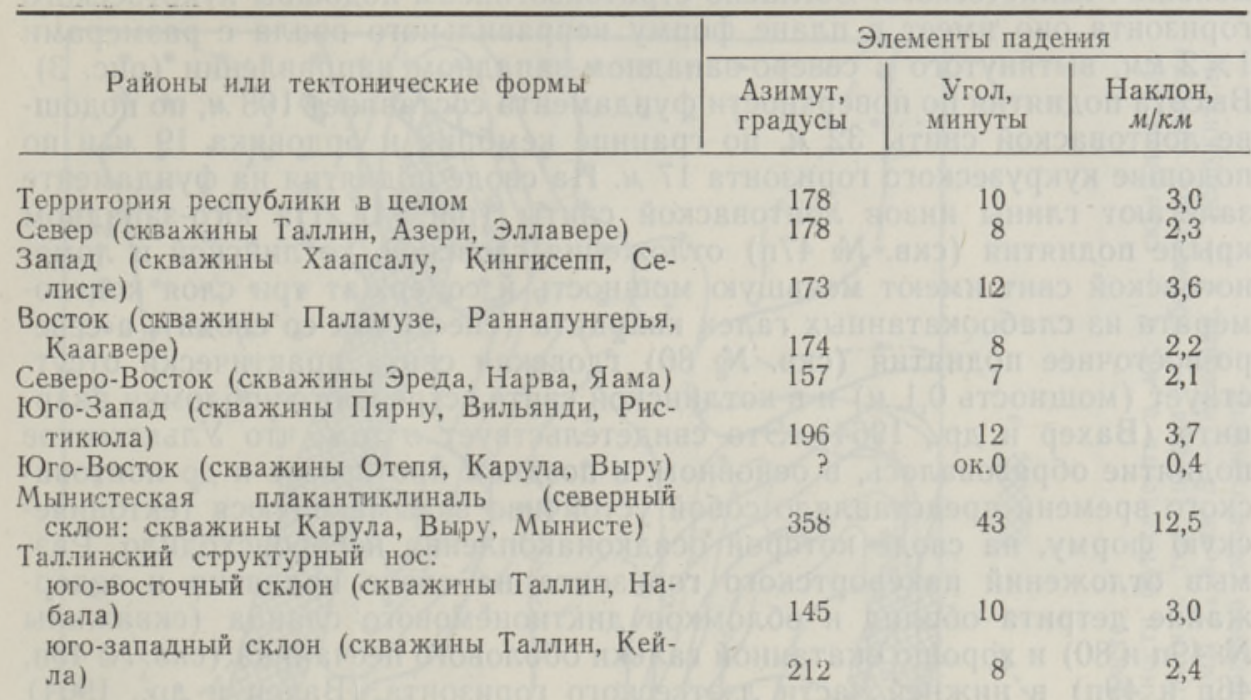

тавляет по данным сейсморазведки 50-60 км, ширина $15-20 \kappa м$, средний наклон северного крыла $2^{\circ} 50^{\prime}(50 \mathrm{M} / \kappa M)$, южного - $11^{\circ} 20^{\prime}$ (200 мікм). По-видимому, местами крылья крутые: в скв. Понкули, по данным Л. Паасикиви (1966), углы падения слоев осадочных пород нижнего палеозоя достигают 55․ Высота поднятия по поверхности фундамента превышает $500 \mathrm{~m}$, по поверхности додевонских огложений состав ляет около $120 \mu$, по подошве наровских слоев около $80 \mu$. На своде поднятия на кристаллическом фундаменте залегают среднедевонские отложения (см. рис. 5 в Каплан, Хазанович, 1969). Отсутствие в разрезе валдайских отложений связано с региональными восходящими движениями, охватывавшими в то время всю Юго-Западную и частично ЮгоВосточную Эстонию. Мынистеское локальное поднятие возникло в конще нижнего кембрия. По А. Каплану и К. Хазановичу, рост его в тискреское время, в ордовике и нижнем силуре не продолжался. Оно сформировалось в основном в конце силура и начале девона, когда его тектоническая активность резко возросла. Это привело к полному размыву осадочного чехла на своде поднятия и частичному на крыльях (Каплан, Хазанович, 1969).

Мынистеское поднятие совпадает в плане с максимумом гравитационной аномалии. Интенсивность аномалии зависит не только от рельефа, но и от петрографической неоднородности фундамента, причем роль последней превышает роль рельефа в несколько раз. Севернее поднятия резкий градиент аномалии силы тяжести огмечает границу распространения гранитоидов, вскрытых скв. Лаанеметса. По данным сейсморазведки северное крыло поднятия находится в пределах гравитационного минимума, обусловленного этими гранитоидами. Южное крыло совпадает с небольшим градиентом аномалии силы тяжести, который, по-видимому, целиком вызван уступом поверхности фундамента. Магнитное поле в пределах поднятия резко переменное. На своде его вычисленные абсолютные отметки верхних кромок магнитных тел колеблются от -130 до -300 м. Эти значения в общєм согласуются с действительным положением поверхности фундамента (по данным сейсморазведки от -215 до -250 м, в скв. Мынисте -232 м). 
Площадь Ульястеского поднятия по данным бурения значительно меньше Мынистеского. Согласно стратоизогипсам подошвы кукрузеского горизонта оно имеет в плане форму неправильного овала с размерами $1 \times 2 \kappa м$, вытянутого в северо-западном-западном направлении (рис. 3). Высота поднятия по поверхности фундамента составляет 108 м, по подошве лонтоваской свиты $32 \mu$, по границе кембрия и ордовика $19 \boldsymbol{\mu}$ и по подошве кукрузеского горизонта 17 . На своде поднятия на фундаменте залегают глины низов лонтоваской свиты (рис. 4). На юго-западном крыле поднятия (скв. № 47п) отложения гдовской, котлинской и ломоносовской свит имеют меньшую мощность и содержат три слоя конгломерата из слабоокатанных галек кварцита (снесенных со свода), а северо-восточнее поднятия (скв. № 80) гдовская свита практически отсутствует (мощность $0,1 \mathrm{M}$ ) и в котлинской свите встречаются обломки кварцита (Вахер и др., 1964). Это свидетельствует о том, что Ульястеское поднятие образовалось, в основном, в позднем протерозое и до лонтоваского времени представляло собой устойчиво вздымающуюся тектоническую форму, на своде которой осадконакопления не происходило. Размыв отложений пакерортского горизонта на своде поднятия и содержание детрита оболид и обломков диктионемового сланца (скважины № 49п и 80) и хорошо окатанной гальки оболового песчаника (скв. № 45п, $46 п$ и 49п) в нижней части лээтсеского горизонта (Вахер и др., 1964) указывают на временное оживление поднятия в раннем ордовике. Судя по высоте поднятия $(17$ м) по подошве кукрузеского горизонта, некоторое вздымание его происходило и после кукрузеского времени (точнее этю оживление датировать нельзя ввиду отсутствия в разрезе более молодых коренных пород).

Ульястеское поднятие совпадает в плане с локальным максимумом гравитационной аномалии интенсивностью (за счет рельефа фундамента) порядка 1 мгл. Там же наблюдается и интенсивный (около 2000 гамм) максимум магнитной аномалии $Z_{\mathrm{a}}$. На своде поднятия вычисленные абсолютные отметки кровли магнитных тел колеблются от -35 до -85 $\mathrm{M}$, а поверхности фундамента по данным бурения от -61 до $-74 \mu$. Совпадение в плане пологих антиклинальных складок, маркированных стратоизогипсамй подошвы кукрузеского горизонта, слабых максимумов гравитационной аномалии, максимумов $Z_{\mathrm{a}}$ и повышенных абсолютных зна. чений верхних кромок магнитных тел указывает на наличие на участке Ульясте еще четырех плакантиклиналей, подобных описанной выше (см. рис. 3). Они группируются в два почти параллельных ряда северо-западного-западного направления. Наибольший градиент аномалии силы тяжести отмечает внешний контур распространения поднятий.

Палукюлаское поднятие в общих чертах совпадает с небольшой (длина $4-5$ и ширина $1 \kappa м$ ) возвышенностью северо-западного простирания на дневной поверхности (см. рис. 1 в Viiding и др., 1969). Высота поднятия по поверхности фундамента составляет 275 м, по подошве верхнего ордовика $90 \mu$ и по кровле раквереского горизонта $75 \mu$. Угол падения северо-восточного крыла равен приблизительно $30-40^{\circ}$, юго-западное крыло более крутое. На своде поднятия на фундаменте залегают верхнеордовикские отложения. По данным Э. Кала*, поднятие возникло в Еалдайское время и свод его устойчиво вздымался до верхнего ордовика. По характеру распространения доверхнеордовикских отложений на крыльях поднятия обнаруживаются дифференциальные движения. Северо-восточное крыло интенсивно погрукалось в нижнем кембрии, а югозагадное - в среднем ордовике. Анализ мощностей верхнеордовикских

* Частное сообщение Э. Кала. 


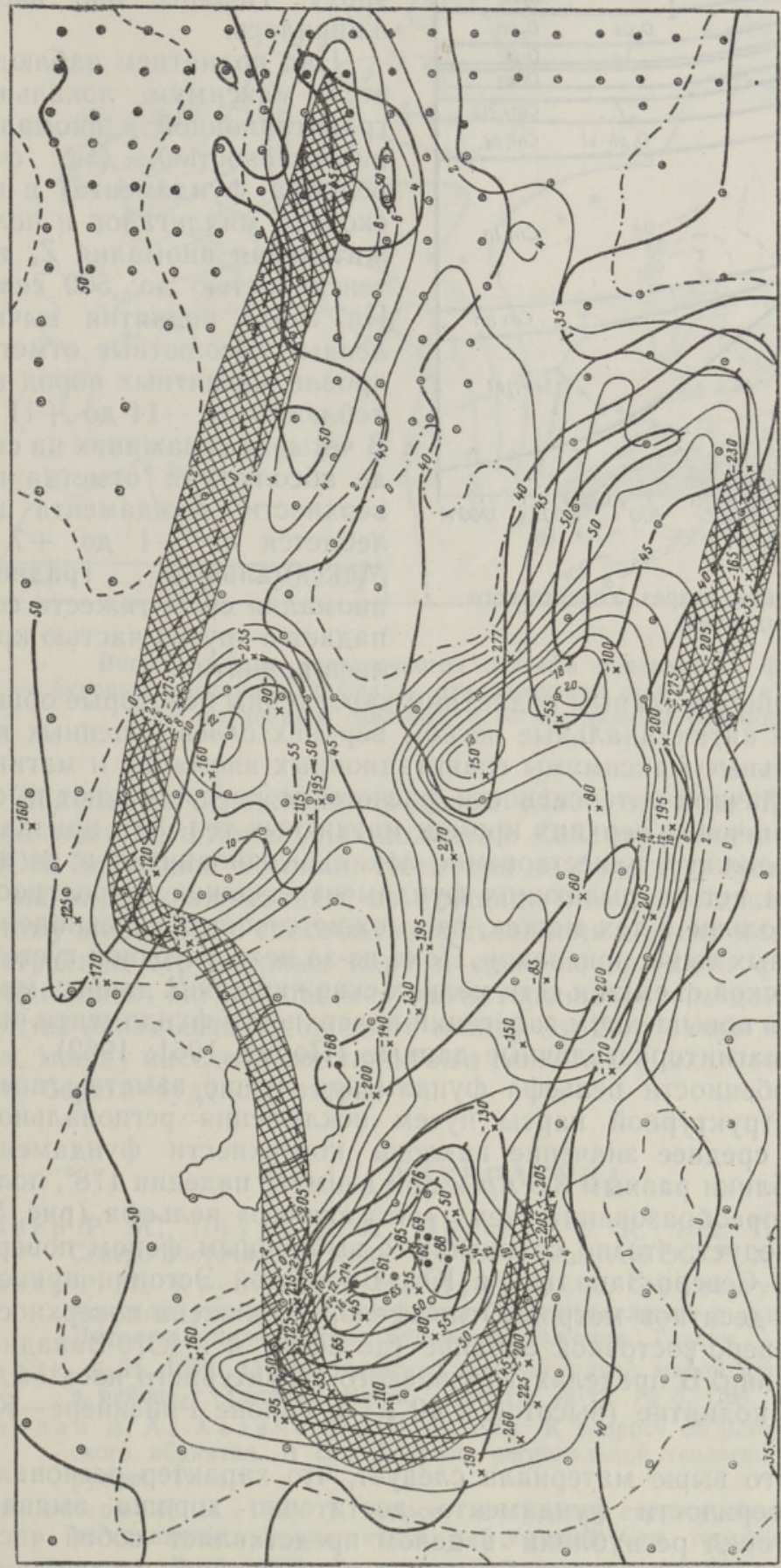

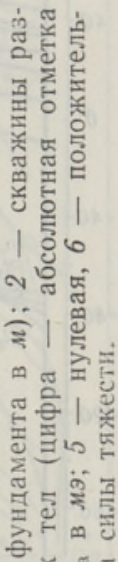

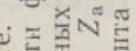

ㄴ.

$>$ 월 인

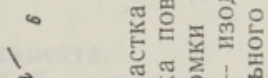

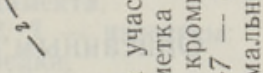

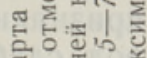

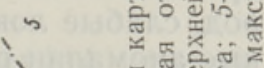

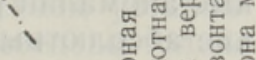

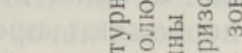

- E윰인

i

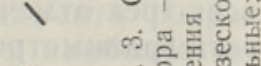

\%

×

* 就兽与

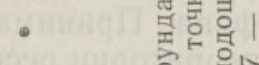

-

的寻莫

获

흘

䓃蔍

㠃。

드.

I 兽市

一觜啲 


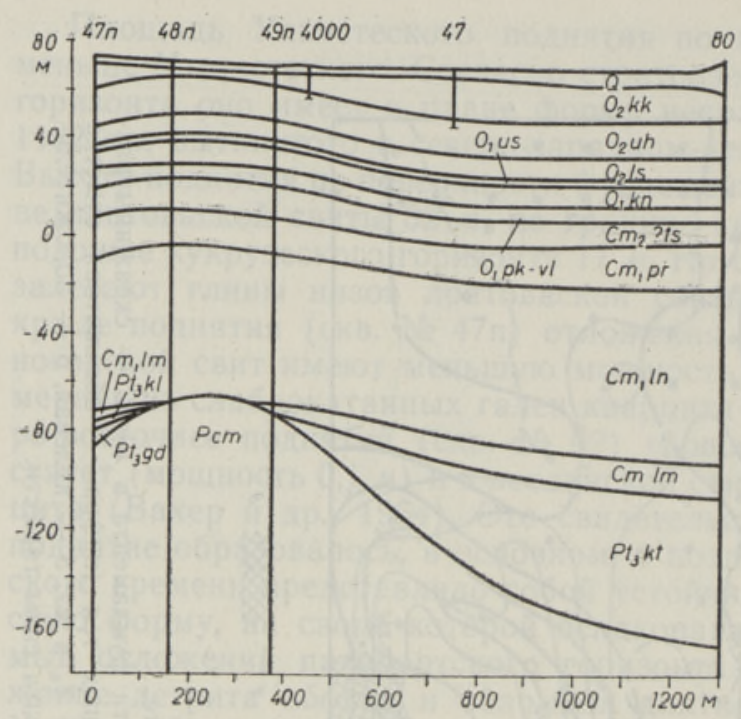

Рис. 4. Геологическнй разрез Ульястеского поднятия. отложений не свидетельствует о развитии поднятия в эту эпоху. Позднее оно вновь оживилось.

Над поднятием наблюдается максимум локальной гравитационной аномалии интенсивностью (за счет рельефа фундамента) в несколько миллигалов и положительная аномалия $Z_{\text {a }}$ интенсивностью до 500 гамм. На своде поднятия вычисленные абсолютные отметки кровли магнитных пород колеблются от -14 до $+11 \mathrm{M}$. В четырех скважинах на своде абсолютная отметка поверхности фундамента колеблется от +1 до $+7 \mu$. Максимальный градиент аномалии силы тяжести совпадает с крутой частью крыльев поднятия.

Описанным выше локальным поднятиям характерны некоторые общие признаки: пологие антиклинальные изгибы верхних слоев коренных пород, слабые локальные максимумы гравитационных аномалий и магнитные аномалии различной интенсивности, расчеты по которым дают высокие абсолютные значения верхних кромок магнитных тел. Эти признаки позволяют предположить сушествование локальных поднятий и на тех участках, где пока нет вскрывающих фундамент скважин. Вероятность их обнаружения больше в тех местах, где можно говорить о совпадении всех трех отмеченных выше признаков. Пока из-за недостаточной густоты сети гравиметрической съемки и сети мелких скважин таких данных мало и предположения о повышенном залегании поверхности фундамента опираются лишь на магниторазведочные данные (Побул, 1961; 1962).

Некоторые особенности рельефа фундамента лучше заметны после преобразования структурной карты путем исключения регионального фона. Принимая среднее значение наклона поверхности фундамента территории республики равным 3,0 м/км при азимуте падения $178^{\circ}$, получим в результате преобразования схему «остаточного» рельефа (рис. 5). Из этой схемы следует, что по сравнению с выбранным фоном поверхность фундамента Северо-Западной и Юго-Восточной Әстонии приподнята на несколько десятков метров. Относительно понижена поверхность фундамента на северо-восточной окраине (до 60 м) и в Юго-Западной (более 50 м) Эстонии. В пределах Таллинского структурного носа выделяется локальное поднятие (высотой в 40 м) в районе Рийзипере-Кохила-Мярьямаа.

Из приведенного выше материала следует, что характер регнонального падения поверхности фундамента достаточно хорошо выявлен бурением. Территория республики в целом представляет собой часть южного склона Балтийского щита. Ее можно подразделить на две зоны, граница которых проходит примерно по линии Таллин-Пярну. В западной зоне общий наклон поверхносги фундамента несколько больше $(3,6 \mu / \kappa M)$, чем в восточной зоне $(2,3 \mu / \kappa M)$. 


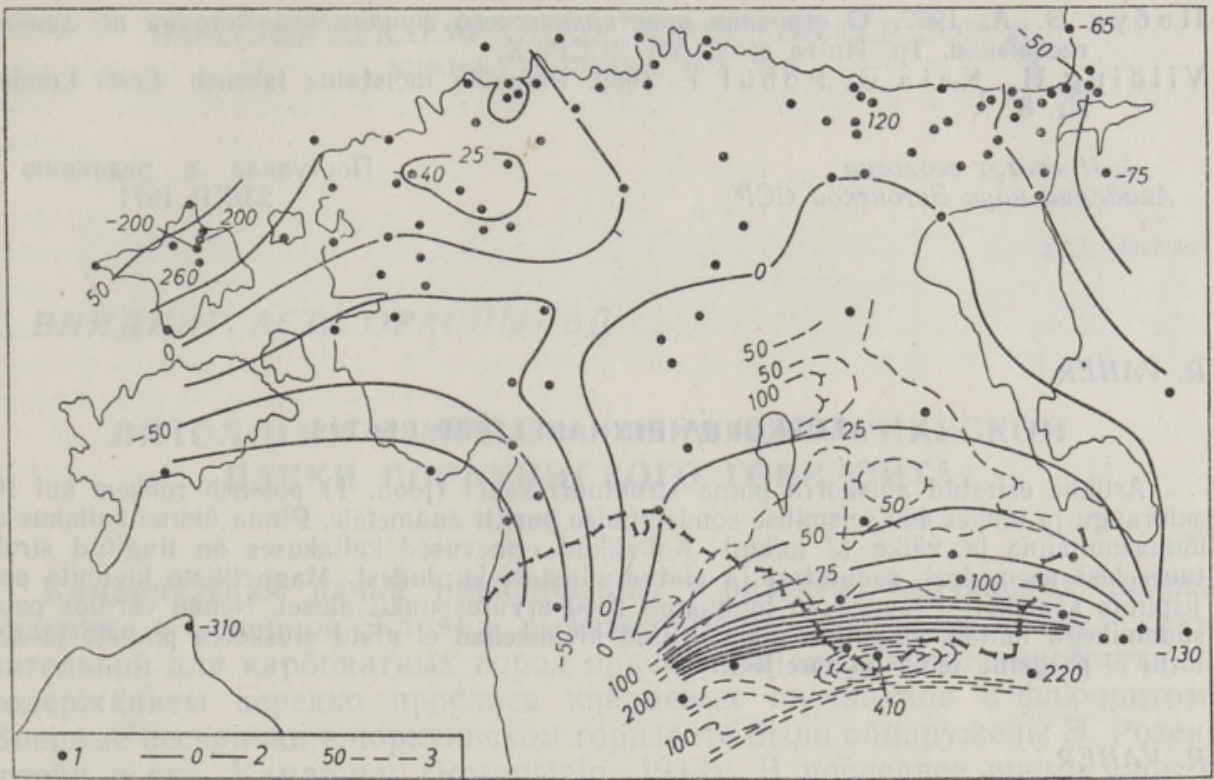

Рис. 5. Схема «остаточного» рельефа поверхности фундамента.

1 - буровые скважины (цифра - относительная отметка в $м$ ); 2,3 - изогипсы:

2 - по данным скважин, 3 - по данным сейсморазведки.

Локальные осложнения в целом слабо изучены. Бурением установлено лишь пять локальных поднятий. Сейсморазведка проведена только в Юго-Восточной Эстонии. Несмотря на большую густоту точек расчета по магнитным аномалиям, по площади они расположены неравномерно. K тому же вопрос о способах использования данных магниторазведки при построении структурных карт и схем поверхности фундамента разработан слабо. По имеющимся магниторазведочным данным наиболее вероятны локальные осложнения между оз. Выртсъярв и Пярнуским заливом, между населенными пунктами Кохила и Пыльтсамаа и вдоль западного берега Чудского озера.

\section{ЛИТЕРАТУРА}

В ахер Р. М., Пуура В. А., Эрисалу Э. К. 1962. Тектоническое строение Северо-Восточной Әстонии. Тр. Ин-та геол. АН ЭССР, Х.

В ахер Р. М., Кууспалу Т. И., Пуура В. А., Эрисалу Э. К. 1964. О геологическом положении сульфидных рудопроявлений в районе Ульясте. В сб.: Литология палеозойскнх отлсжений Әстонин. Таллин.

Верте А. И. 1959. О тектонической природе одной малой куполовидной структуры в районе г. Таллина. Вестн. Ленингр. ун-та, № 6, Сер. геол. и геогр., вып. 1.

Ка пл ан А. А., Х азанов ич К. К. 1969. К вопросу об истории развития Локновского поднятия. В сб.: Вопросы региональной геологии Прибалтики и Белоруссии. Рига.

М их айлов Н. Н. 1960. К вопросу построения структурных схем по материалам региональных аэромагнитных наблюдений. Сов. геология, № 4 ,

П а а с и ки в и Л. Б. 1966. Геологическое строение и иетория развития Хаанья-Локновского и Мынистеского поднятий. В сб.: Вопросы разведочной геофизики, вып. 5. Л.

Побул Э. А. 1961. О рельефе кристаллического фундаменга на территории Эстонской ССР. Тр. Ин-та геол. АН әССР, VI. 
Побул Э. А. 1962. О строении кристаллического фундамента Эстонии по данным геофизики. Тр. Ин-та геол. АН ЭССР, Х.

Vi iding H., Kal a E., P obul E. 1969. Paluküla mõistatus laheneb. Eesti Loodus, Nr. 8.

\author{
Институт геологии \\ Академии наук Эстонской ССР \\ Поступила в редакцию \\ 23/XII 1971
}

\title{
R. VAHER
}

\section{ALUSKORRA PINNARELJEEF EESTIS}

Artiklis esitatud aluskorra pinna struktuuri kaart (joon. 1) põhineb rohkem kui 100 puuraugu ja umbes 400 seismilise sondeerimise punkti andmetele. Pinna üldine kallakus on lōunasuunaline ja väike $(3 \mathrm{~m} / \mathrm{km})$. Kohalikud erinevused kallakuses on tingitud struktuursetest neemedest, sadulatest ja platvormilistest kurdudest. Magnetiliste kivimite pealispinna samakôrgusjooned on tômmatud 2300 arvutuspunkti alusel. Nende vôrdlus puursüdamikega näitab, et paljud magnetilised kivimkehad ei ulatu aluskorra pinnale ja seetôttu ei peegelda tema pinnareljeefi.

\section{R. VAHER}

\section{PRECAMBRIAN BASEMENT RELIEF OF ESTONIA}

The main features of the subsurface basement relief of Estonia are known from available drilling data and geophysical information. The structure contour map of the basement surface presented in this paper (Fig. 1) is based upon more than 100 borings distributed fairly well throughout the area, and about 400 seismic depth estimates available in the south-eastern part of the area only. The regional southward dip of the basement surface is rather small $(3 \mathrm{~m}$ per $\mathrm{km})$. Several local dips are computed on the basis of drilling data (see Table). Local dips are due to such structural features as structural noses, saddles and local uplifts (closures). A close inspection of the geological crosssections of the 3 local uplifts reveals that they are plain-type folds (Fig. 4). The magnetic basement map (Fig. 1) was contoured on the basis of about 2300 magnetic depth estimates. This map is compared with the basement's surface depths at the 60 points drilled to the basement. The errors of the computed depth estimates are biased toward the deep side (Fig. 2). Obviously there are many units of magnetization within the basement rocks, whose upper surfaces are deeper than the basement's surface and, consequentiy, they do not represent the basement relief. 